\title{
Bacterial Ribosomes and Protein Synthesis
}

\author{
By K. MCQUILLEN \\ Department of Biochemistry, University of Cambridge
}

Bacterial cells, like other living organisms, contain ribonucleic acid (RNA) both free and in combination as ribonucleoprotein (RNP). The free, or soluble, RNA has a composition different from, and a molecular weight (c. 30,000) lower than, that of combined RNA. Neither has a composition obviously related to that of the deoxyribonucleic acid (DNA). In addition to the usual four nucleotides, soluble RNA contains pseudo-uridylic acid, and much of this RNA is thought to function in the transfer of activated amino acids to the site of synthesis of protein. This fraction is known as 'S-RNA' or 'transfer-RNA' or 'acceptor-RNA'. Most of the RNA, however, can be isolated from disrupted cells as ribosomes which are RNPparticles of sedimentation constant in the range $20 S$ to $100 S$. There is controversy as to whether such particles exist in vivo and, if so, which sizes occur within living cells. The proportions of the different sizes obtainable from bacteria depend on various factors such as the cultural conditions (growth medium, phase of growth, presence of antibiotics) and the nature of the medium in which the preparation is made. The 'fundamental particles' appear to be $30 S$ and $50 S$ and combination of one of each of these yields a $70 \mathrm{~S}$ ribosome. Dimerization of the latter gives $100 \mathrm{~S}$ particles. These changes can be brought about by altering the $\mathrm{Mg}^{2+}$ concentration in the medium:

$$
\begin{aligned}
& 100 S \rightleftharpoons 2(70 S) \rightleftharpoons 2(30 S+50 S) \rightarrow \text { Disintegration. } \\
& \mathrm{Mg}^{2+} \text { concentration decreasing } \longrightarrow
\end{aligned}
$$

Isolated ribosomes appear by electron microscopy to be 100-200 $\AA$. in diameter (Hall \& Slayter, 1959; Huxley \& Zubay, 1960) and ultrathin sections of bacterial cells if suitably fixed show the cytoplasm to contain electron-dense particles of similar size. There is no indication of an endoplasmic reticulum to which these particles are attached as in some mammalian tissue cells but the particles are generally believed to be ribosomes. On disrupting the cell they are released and, after removing the large cell fragments, can be sedimented by centrifugation for 1-3 hr. at $100,000 \mathrm{~g}$. The various sizes can be separated by differential centrifugation or by spinning down through a solution of increasing density, e.g. a sucrose gradient from 5 to $20 \%(\mathrm{w} / \mathrm{v})$ (Britten \& Roberts, 1960).

When highly purified, ribosomes consist of 50-65 \% RNA and 50-35\% protein, and contain cations such as $\mathbf{M g}^{2+}$ or possibly polyamines (putrescine, spermidine, spermine) but no detectable lipid or DNA. The protein is thought to be largely 'structural' and can be separated into more than two dozen basic proteins of average molecular weight about 25,000 (Waller \& Harris, 1961). In Escherichia coli 80-90\% of these protein chains have $\mathrm{N}$-terminal alanine or methionine but whether each ribosome contains all kinds or only one kind is not known. The total protein in $30 S$ and $50 S$ particles would correspond to molecular weights of about 300,000 and 600,000 respectively. 
Nucleotides of adenine, guanine, uracil and cytosine are the major constituents of the RNA of ribosomes and the small amounts of pseudo-uridylic acid which are sometimes found may be due to contamination or transient association with transfer-RNA. $30 S$ ribosomes contain a single unit of RNA (molecular weight $c .500,000$, sedimentation constant 14-16S); the 50S particles contain either two such units or one unit of twice the size $(c .23 S)$. These high-molecular-weight units can be degraded into subunits by heat, controlled dialysis and other treatments. The relative dispositions of the RNA and protein in ribosomes are not known with certainty but the particles may be sponge-like in form, carrying several times their own weight of water and with the RNA more exposed than in the small RNA viruses.

In addition to containing RNA and structural protein, ribosome preparations frequently exhibit enzymic activity. Much of this may be due to non-specific binding but there is reason to believe that some is inherent. Most of the ribonuclease activity of bacterial cells is demonstrable in purified ribosomes but is latent until the particles have been disrupted, e.g. by urea or chelating agents (Elson, 1961; Bolton et al. 1959). Unmasking results in digestion of ribosomal as well as added RNA. Latent deoxyribonuclease activity (Elson, 1961) and non-latent peptidase activity (Bolton et al. 1959) have also been reported. Finally, traces of all kinds of proteins may be present as nascent material at its site of synthesis (McQuillen, Roberts \& Britten, 1959; Roberts et al. 1960).

There is abundant evidence from in vivo and in vitro experiments that ribosomes are concerned in the synthesis of protein in animals, plants and micro-organisms (McQuillen, 1962). When radioactive precursors to proteins (amino acids or inorganic sulphate) are fed to a growing culture of bacteria, the radioactivity is incorporated in 'nascent protein' bound to ribosomes before appearing in the soluble protein fraction of the cells (McQuillen et al. 1959). This is an extremely rapid process and to demonstrate the higher specific radioactivity of the nascent protein it was necessary to carry out in vivo experiments lasting only a few seconds. The ribosomes became maximally labelled in 5-10 seconds and the radioactivity was 'chased out' by unlabelled substrates equally rapidly. The radioactivity associated with ribosomes was present in amino acids linked as polypeptides or proteins. Even when ${ }^{35} \mathrm{SO}_{4}{ }^{2-}$ was used for only a few seconds, radioactive cysteine and methionine were found in a number of peptides on partial hydrolysis of the ribosomes. Although this association is transient in vivo, it is quite stable in vitro and nascent protein has only been removed by treatments which disrupt the ribosomes, e.g. 4M-urea (McQuillen, 1961).

Preparations were usually made in media containing $\mathrm{Mg}^{2+}(0.005-0.01 \mathrm{M})$ such that most of the ribosomes were in the $70 S$ or larger form. Reduction to $0.0001 \mathrm{M}$ $\mathrm{Mg}^{2+}$ caused dissociation of the bulk of these to $50 S+30 S$ particles which could be separated by centrifugation through a sucrose gradient. Nevertheless, a great deal of the nascent protein still occurred in the $70 S$ region, which now contained only a few ribosomes (McQuillen et al. 1959). It may be that a small fraction of the ribosomes exists in a form which does not readily dissociate and on which the nascent protein is synthesized. Studies with cell-free fractions of Escherichia coli support this possibility. Lamborg \& Zamecnik (1960) devised a system containing ribosomes and soluble factors which converted amino acids to peptides or proteins. 
This was investigated further by Tissières, Schlessinger \& Gros (1960) who showed that the newly synthesized polypeptides were principally associated with the $70 \mathrm{~S}$ region even when reduction of $\mathrm{Mg}^{2+}$ concentration had caused the dissociation of the majority of the $70 S$ ribosomes to $50 S+30 S$ particles. It was estimated that 5-10\% of the ribosomes might be in a non-dissociating, 'active $70 S$ ' form. $30 S$ and $50 S$ particles had been previously shown to reassociate to $70 S$ when the $\mathrm{Mg}^{2+}$ concentration was restored to $0.01 \mathrm{~m}$ but this procedure did not yield ' active $70 S$ ' ribosomes.

Until recently it was generally assumed that the RNAs of ribosomes acted as templates for organizing the synthesis of the many different kinds of protein. Each bacterial cell contains 10,000 or more ribosomes and makes perhaps 1000 different proteins, and it is important to know whether or not different proteins can be made on the same ribosome or whether a specific kind of ribosome is needed for each specific protein. If DNA in the nucleus transmits 'information' to RNA which then specifies the sequence in which amino acids are joined to form proteins, it is reasonable to hypothesize that the information might involve the sequence of the nucleotides in the DNA and RNA and, therefore, that there might be expected some relation between DNA and RNA composition. Although there is no apparent correlation between DNA and ribosomal RNA, in several systems there has been found an RNA component which resembles DNA in nucleotide composition. The concept of 'messenger-RNA' has been developed (Brenner, Jacob \& Meselson, 1961; Jacob \& Monod, 1961). 'Ribosomes are non-specialized structures which synthesize, at a given time, the protein dictated by the messenger they happen to contain' (Brenner et al. 1961). This 'messenger-RNA' or 'tape-RNA' (Bonner, 1961) is said to be made in association with DNA and to have a related composition; to be heterogeneous in molecular weight (this is necessary since it is to 'code' for proteins of different sizes) but averaging not less than 500,000; to associate with ribosomes in order to 'programme' them; and to have a turnover rate such that each 'messenger-RNA' is used only once or a few times (Jacob \& Monod, 1961). Much of the experimental evidence on which this theory is based comes from investigations of organisms infected with bacteriophage (Volkin \& Astrachan, 1956; Volkin, 1960; Brenner et al. 1961; Spiegelman, Hall \& Storck, 1961). Infection may halt the synthesis of the many proteins previously made by the host, initiate synthesis of 20-30 new proteins concerned in phage production, and lead to the synthesis and turnover of an RNA fraction with properties like those mentioned above. Formation of completely new ribosomes is not, apparently, involved but the new RNA may associate with pre-existing ribosomes. A similar mechanism (i.e. transient association of specific 'messenger-RNA' with ribosomes) has also been suggested for uninfected Escherichia coli (Gros et al. 1961; Jacob \& Monod, 1961) but the evidence is not conclusive. A puzzling feature is that the material identified with the postulated 'messenger-RNA' has kinetic properties required of a precursor of ribosomal-RNA - amount, rate of synthesis, etc. Moreover, there are other systems (e.g. reticulocytes) in which protein synthesis occurs without concomitant turnover of a component corresponding to 'messenger-RNA'. Roberts and his colleagues (McCarthy \& Britten 1962; Britten \& McCarthy 1962; McCarthy, Britten \& Roberts, 1962 ; Britten, McCarthy \& Roberts, 1962) in a very detailed investigation have shown the necessity for, and have demonstrated the occurrence of, a precursor of ribosomal RNA in uninfected $E$. coli. This material sediments in the same region 
as the 'messenger-RNA' (8-14S), amounts to the same fraction of the total RNA (c. $3 \%$ ), becomes labelled equally rapidly (maximally in 1-2 min.) and is not conserved in this form, i.e. it is transferred elsewhere or broken down. The evidence presented suggests that after synthesis this RNA becomes incorporated into new ribosomes rather than being degraded. The possibility that the "information' or 'message' may be conserved or 'buried' in ribosomes together with additional nucleotides which alter the overall composition cannot yet be excluded. Moreover, there must be explanation of the whereabouts of the necessary ribosomal RNA precursors which are not apparent in the scheme of Gros et al. (1961) and an indication of the function of ribosomal RNA if it is not mainly 'information'. It is, after all, 60-90\% of the total RNA and is conserved during growth.

The author was a Research Associate of the Carnegie Institution of Washington.

\section{REFERENCES}

Bolton, E. T., Britten, R. J., Cowie, D. B., McCarthy, B. J., McQuillen, K. \& Roberts R. B. (1959). Annual Report of the Biophysics Section. Yearb. Carneg. Inst. 58, 259.

Bonner, J. (1961). Discussion. In Protein Biosynthesis, p. 205. Ed. by R. J. C. Harris. London: Academic Press.

Brenner, S., JACOB, F. \& Meselson, M. (1961). An unstable intermediate carrying information from genes to ribosomes for protein synthesis. Nature, Lond. 190, 576.

Britten, R. J. \& McCarthy, B. J. (1962). The synthesis of ribosomes in E. coli II. Analysis of the kinetics of tracer incorporation in growing cells. Biophys. J. 2, 49.

Britten, R. J. \& Roberts, R. B. (1960). High-resolution density gradient sedimentation analysis. Science, 131, 32.

Britten, R. J., McCarthy, R. J. \& Roberts, R. B. (1962). The synthesis of ribosomes in E. coli. IV. The synthesis of ribosomal protein and the assembly of ribosomes. Biophys. J. $2,83$.

ELson, D. (1961). Biologically active proteins associated with ribosomes. In Protein Biosynthesis, p. 291. Ed. by R. J. C. Harris. London: Academic Press.

Gros, F., Hiatt, H., Gilbert, W., Kurland, C. G., Risebrovgh, R. W. \& Watson, J. D. (1961). Unstable ribonucleic acid revealed by pulse labelling of Escherichia coli. Nature, Lond. 190, 581.

Hall, C. E. \& Slayter, H. S. (1959). Electron microscopy of ribonucleoprotein particles from E. coli. J. mol. Biol. 1, 329.

HuXIEY, H. E. \& ZuBAY, G. (1960). Electron microscope observations on the structure of microsomal particles from Escherichia coli. J. mol. Biol. 2, 10.

$\mathrm{J}_{\mathrm{ACOB}}, \mathrm{F}$. \& MONOD, G. (1961). Genetic regulatory mechanisms in the synthesis of proteins. J. mol. Biol. 3, 318.

Lamborg, M. R. \& ZameCNiK, P. C. (1960). Amino acid incorporation into protein by extracts of $E$. coli. Biochim. biophys. Acta, 42, 206.

McCarthy, B. J. \& Britten, R. J. (1962). The synthesis of ribosomes in $\boldsymbol{E}$. coli. I. The incorporation of $\mathrm{C}^{14}$-uracil into the metabolic pool and RNA. Biophys. J. 2, 35 .

McCarthy, B. J., Britten, R. J. \& Roberts, R. B. (1962). The synthesis of ribosomes in $E$. coli. III. Synthesis of ribosomal RNA. Biophys. J. 2, 57.

McQuillen, K. $(1961 a)$. Protein synthesis in vivo: the involvement of ribosomes in Escherichia coli. In Protein Biosynthesis, p. 263. Ed. by R. J. C. Harris. London: Academic Press.

McQuillen, K. (1961 b). Ribosomes and the synthesis of proteins. Progr. Biophys. biophys. Chem. 12, 69.

McQuiluen, K., Roberts, R. B. \& Britten, R. J. (1959). Synthesis of nascent protein by ribosomes in Escherichia coli. Proc. nat. Acad. Sci., Wash. 45, 1437. 
Roberts, R. B., Aronson, A. I., Bolton, E. T., Britten, R. J., Cowie, D. B., Duerksen, J. D., McCarthy, B. J. \& McQuillen, K. (1960). Annual Report of the Biophysics Section. Yearb. Carneg. Inst. 59, 229.

Spiegelman, S., Hall, B. D. \& Storck, R. (1961). The occurrence of natural DNARNA complexes in Escherichia coli infected with T2. Proc. nat. Acad. Sci., Wash. 47, 1135.

Tissik̀res, A., Schlessinger, D. \& Gros, F. (1960). Amino acid incorporation into proteins by Escherichia coli ribosomes. Proc. nat. Acad. Sci., Wash. 46, 1450.

Volkin, E. (1960). The function of RNA in T2-infected bacteria. Proc. nat. Acad. Sci., Wash. 46, 1336.

Volkin, E. \& Astrachan, L. (1956). Phosphorus incorporation in Escherichia coli ribonucleic acid after infection with bacteriophage T2. Virology, 2, 149.

Waller, J.-P. \& Harris, J. I. (1961). Studies on the composition of the protein from Escherichia coli ribosomes. Proc. nat. Acad. Sci., Wash. 47, 18. 